Original Article

\title{
THE POSSIBILITY OF DEVELOPMENT OF ANTIBIOTIC RESISTANCE FROM MASSIVE AND UNCONTROLLED USE OF SULFONAMIDES IN MILK
}

\author{
ZANA IBRAIMI ${ }^{1}$, AGIM SHEHI $^{2}$, ARDIANA MURTEZANI ${ }^{3}$, FEHIM HALITI ${ }^{4 *}$
}

${ }^{1}$ Department of Pharmacy, Faculty of Medicine, University of Prishtina-Kosovo, ${ }^{2}$ Institute of Public Health, Faculty of Medicine, University of Tirana-Albania, ${ }^{3}$ Physical Medicine and Rehabilitation Clinic, University Clinical Center of Kosovo, ${ }^{4}$ Department of Children Dentistry, University Dentistry Clinical Center of Kosovo

Email: fehimemahaliti@gmail.com

Received: 26 Jan 2017 Revised and Accepted: 02 Mar 2017

\section{ABSTRACT}

Objective: The aim of this study was to discover sulfa residues in milk and to determine the most appropriate time required for allowing the consumption of milk after drug's use in dairy cattle.

Methods: 150 samples of raw milk were collected from 95\% of dairy farms in Kosovo that were visited during years 2015-2016. At these farms, using a questionnaire, we have identified the treatment procedures of dairy cattle, the dose and the type of drug administered to them, as well as the duration of this administration. Then, ELISA screening method and High-Performance Liquid Chromatography with Fluorescence Detection (HPLC/FD) confirmatory method were used to analyse the collected samples.

Results: Out of 150 milk samples, $52 \%$ were given a combination of $400 \mathrm{mg}$ sulfadiazine $+80 \mathrm{mg}$ trimethoprim, with a statistically significant difference compared to other sulfonamides $\mathrm{p}<0.01$. During the examination by ELISA method, 8 of them (5\%) had exceeded the limit of detection, while during the examination by HPLC/FD method, 4 of them (2.5\%) had exceeded the maximum residue limit allowed. In the first $4 \mathrm{~d}$ after the treatment has ended, the level of sulfonamide residues was high $141.5 \%$, which is as high as their initial dose, with statistically significant linear trend $\mathrm{p}<0.01$.

Conclusion: This study demonstrates that in the collected raw milk there were sulfonamide residues, whose level has fallen following $4 \mathrm{~d}$ of treatment of the animal. It also shows the necessary time allowed for milk consumption. During this time milk must not be consumed in order to prevent the development of antibiotic resistance in the human population.

Keywords: Antibiotic resistance, Sulfonamides, Residues, Milk, ELISA, HPLC

(C) 2017 The Authors. Published by Innovare Academic Sciences Pvt Ltd. This is an open access article under the CC BY license (http://creativecommons.org/licenses/by/4.0/) DOI: http://dx.doi.org/10.22159/ijpps.2017v9i4.17298

\section{INTRODUCTION}

Milk is a primary source of nutrition for humans. It is irreplaceable for the human diet, being very rich in vitamins and calcium. As such it must be pure, uncontaminated by residues coming from either antibiotics or supplements, which when transmitted from animals to humans, can cause a range of diseases harmful to the health of the consumer, as is anti-bioresistance [1, 2].

Antibiotic resistance occurs when an organism is able to survive the exposure of an antibiotic [3, 4]. Microorganisms that are resistant to this exposure, which usually occurs due to uncontrolled use of antibiotics, are transmitted from animals to humans via the consumption of food products, such as milk, meat, honey and eggs (fig. 1) [5, 6].

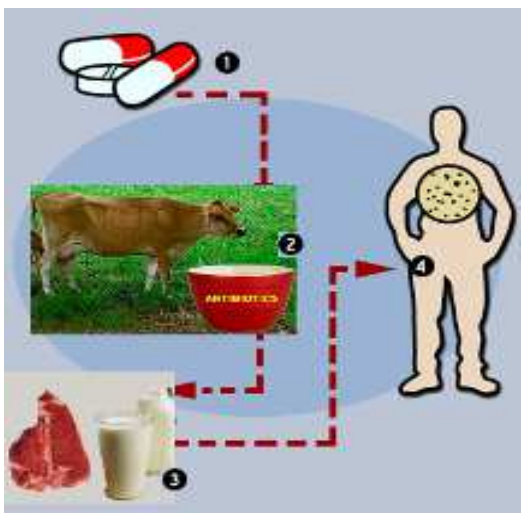

Fig. 1: The spread of antibiotic residues causing antibioresistance [5]
Currently, sulfonamides are the most commonly used antimicrobials in the treatment of food-producing animals due to low cost and easy administration [7]. Unfortunately, in some countries, besides being used for medical treatment they are also given to animals orally, as additives stimulating fattening, to increase food production [8]

However, the main risk of their excessive use in animals is that bacteria can develop resistance, resulting in an increased number of pathogenic bacterias resistant to these antibiotics, ultimately causing serious problems to human health [9].

Other factor to the risk of developing resistance to these drugs is the low doses of sulfonamides being given to animals, at short periods of treatment [10]. If cows are given low doses of sulfonamides, their low concentrations will remain in milk for a much longer time, which would have major consequences for public health [11]

Sulfonamides are one of the oldest group of antimicrobial agents, known as sulfadroga. They have a wide spectrum of action, mainly bacteriostatic, tackling gram positive and negative organisms [12]. Viewed from their chemical content, sulfonamides are amides of the p-aminobenzene sulfonic acid and $N_{1}$-derivatives of sulfanilamide. Substitute in $N_{1}$ position may differ, as it influences the drug's plasma half-life (fig. 2) [13].<smiles>[R]NS(=O)(=O)c1ccc(N)cc1</smiles>

Fig. 2: Base structure of sulfonamides [13] 
The aim of this study was to discover sulfa residues in milk and to determine the most appropriate time required to allow for milk consumption, after drug's use in dairy cattle.

\section{MATERIALS AND METHODS}

For the collection of milk samples from cows treated with sulfonamides over $95 \%$ of livestock farms were visited throughout the territory of Kosovo during the period, June 2015-June 2016.

Within this period, a total of 150 samples of raw milk were collected.

Samples were taken only from cows treated with sulfonamides, calculating only the maximum time of two weeks of treatment and starting from the date of administering the drugs to these sick cattle.

Using a questionnaire we identified the treatment plan, the dose and the type of drug used, as well as the duration of their administration to the cattle.

Sample analysis was carried out in the Veterinary Institute in Skopje, using ELISA screening method and High-Performance Liquid Chromatography with Fluorescence Detection (HPLC/FD) confirmatory method.

ELISA method is one of the fastest and most realiable of analytical methods in detecting the presence of sulfonamides. The preparation of samples of raw milk was made according to the procedures recommended by the packaging manufacturer ELISA (Europroxima, 5101SULM1) [14].

Using HPLC/FD confirmatory analysis we continued to prove the presence of sulfonamide residues in milk samples, apart from those detected by ELISA screening method, according to the defined limit, 'greater than normal'. Selection of fluorescent detection was made due to its high sensitivity, defining only fluorescent compounds, while those that do not show fluorescent compounds were removed from the matrix [15-18].

Methods' accuracy was controlled and calculated based on the maximum permissible limit of sulfonamide residues conform to the regulatory recommendation of Regulation, no. 657/2002 and Regulation of European Directive, no. 96/23/EC, which for ELISA screening method the limit is $13.3 \mu \mathrm{g} / \mathrm{kg}$, whereas for HPLC/FD confirmatory method the limit is $100 \mu \mathrm{g} / \mathrm{kg}[19,20]$.

\section{Statistical analysis}

The collected data were analyzed with SPSS version 12.0 program with a significance level of 0.5 . Categorical variables were tested with the chi-square test $(\chi 2)$, while for the continuous analysis data t-test and Mann-Whitney test was applied.

\section{Ethical clearance}

The study was approved by the Regional Ethical Board at the Food and Veterinary Agency of Kosovo, no 23-2805/174.

\section{RESULTS}

Table 1 shows the number and percentage of cattle treated with sulfonamides. In large percentage, to a $52 \%$, of cattle, a combination of $400 \mathrm{mg}$ sulfadiazine+80 $\mathrm{mg}$ trimethoprim was given, which has a statistically significant difference compared to other sulfonamides $\mathrm{p}<0.01$. The table also shows 4 types of sulfonamides that were mainly used for the treatment.

Table 1: Number and percentage of cattle treated with sulfonamides

\begin{tabular}{|c|c|c|c|}
\hline Sulfonamides & $\mathbf{N}$ & $\%$ & P-value \\
\hline Sulfadiazine $400 \mathrm{mg}+$ Trimethoprim $80 \mathrm{mg}$ & 78 & 52 & 0.01 \\
\hline Sulfadimidine $1000 \mathrm{mg}$ & 22 & 15 & \\
\hline Sulfametoxazole $200 \mathrm{mg}+$ Trimethoprim $40 \mathrm{mg}$ & 39 & 26 & \\
\hline Sulfadiazine $200 \mathrm{mg}+$ Trimethoprim $40 \mathrm{mg}$ & 2 & 1.4 & \\
\hline
\end{tabular}

Fig. 3 shows samples contaminated with sulfonamide residues, during the examination using ELISA method. 8 of them (5\%) had exceeded the limit of detection (LOD) which is $13.3 \mu \mathrm{g} / \mathrm{kg}$.
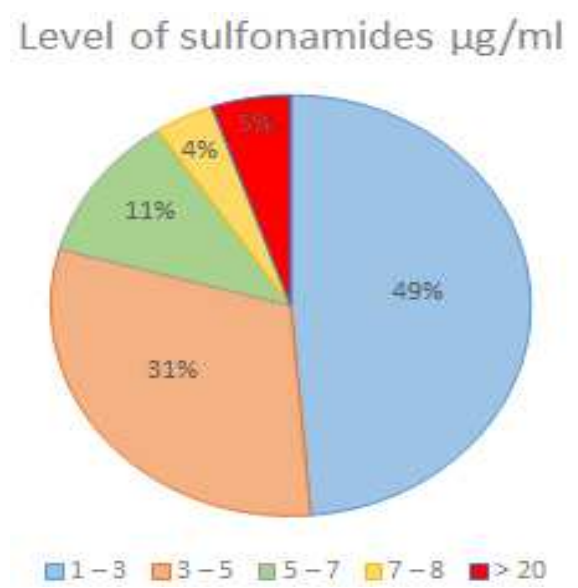

Fig. 3: Level of sulfonamide residues analyzed by ELISA method

Fig. 4 shows the percentage of sulfonamide residues analyzed by HPLC/FD. These 8 samples were analyzed first by ELISA, 4 of which emerged prior to have exceeded the maximal limit allowed, which was $100 \mu \mathrm{g} / \mathrm{kg}$, to an extremely high level, up to nearly $100 \%$.

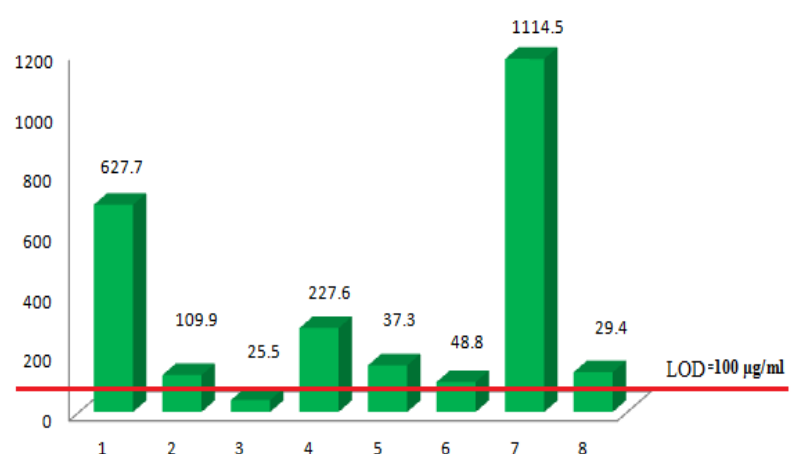

Fig. 4: Level of sulfonamide residues analyzed by HPLC/FD method

Table 2 shows a comparison of the level of sulfonamide residues in milk depending on the time of their administering to cattle. Here it can be clearly seen that during the early days after the treatment has ended the level of residues in milk was quite high. At first 1-4 d, the level was $141.5 \%$, thus being as high as their initial dose, which, in turn, also shows that sulfonamides are drugs that cannot easily be removed from the cattles' bodies. Over time the level of residues in milk was significantly reduced. However, sulfonamide residues were present in milk even after $17 \mathrm{~d}$, albeit in small amounts. The linear trend was statistically quite significant here, respectively $p<0.01$. The results also warn that milk must not be consumed in the first $4 \mathrm{~d}$ after the treatment has ended, thus making it a general time norm for milk consumption. 
Table 2: The comparison level of sulfonamide residues in milk depending on the time of their application

\begin{tabular}{ll}
\hline Time calculated in days & Level of sulfonamides \\
\hline SD & SD \\
\hline (min-max) & (min-max) \\
\hline $1.7(1.5)$ & $141.5(9.1)$ \\
$(1-4)$ & $(129.2-149.2)$ \\
$5.0(3.9)$ & $9.3(4.9)$ \\
$(1-14)$ & $(6.1-21.7)$ \\
$5.6(3.9)$ & $2.8(1.1)$ \\
$(1-17)$ & $(1.1-5.9)$ \\
\hline
\end{tabular}

This comparison is clear even on fig. 5 , which is worked out using $\mathrm{Hi}$ square $\chi 2$ test. It shows that the level of residues is very high in the early times after the treatment has ended, whereas it is decreasing over time.

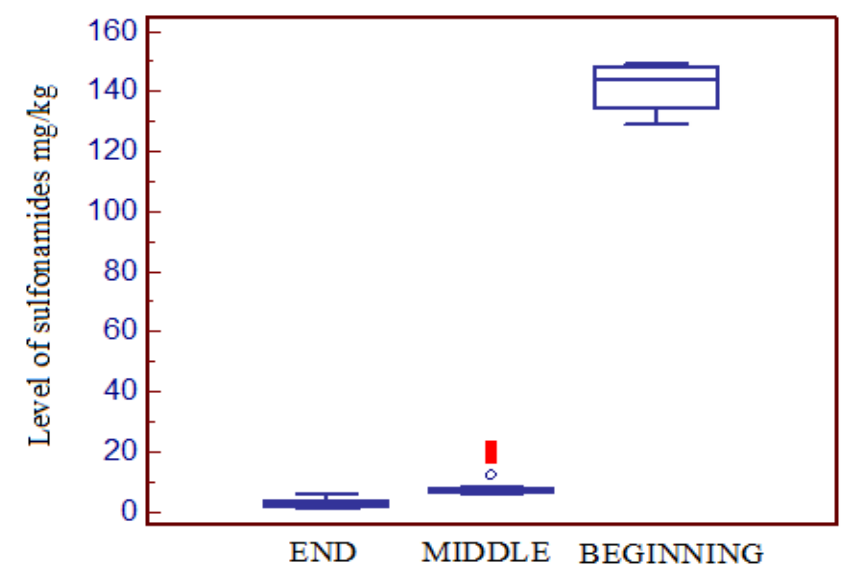

Fig. 5: The comparison level of sulfonamide residues in milk depending on the time of their application

Fig. 6 shows the duration of the treatment, respectively the percentage of cattle treated with sulfonamides according to the number of days. As it is evident, in most cases, the treatment was not carried out according to the protocol. The various doses of drugs were given to cattle for two days only, during the first and the third day.

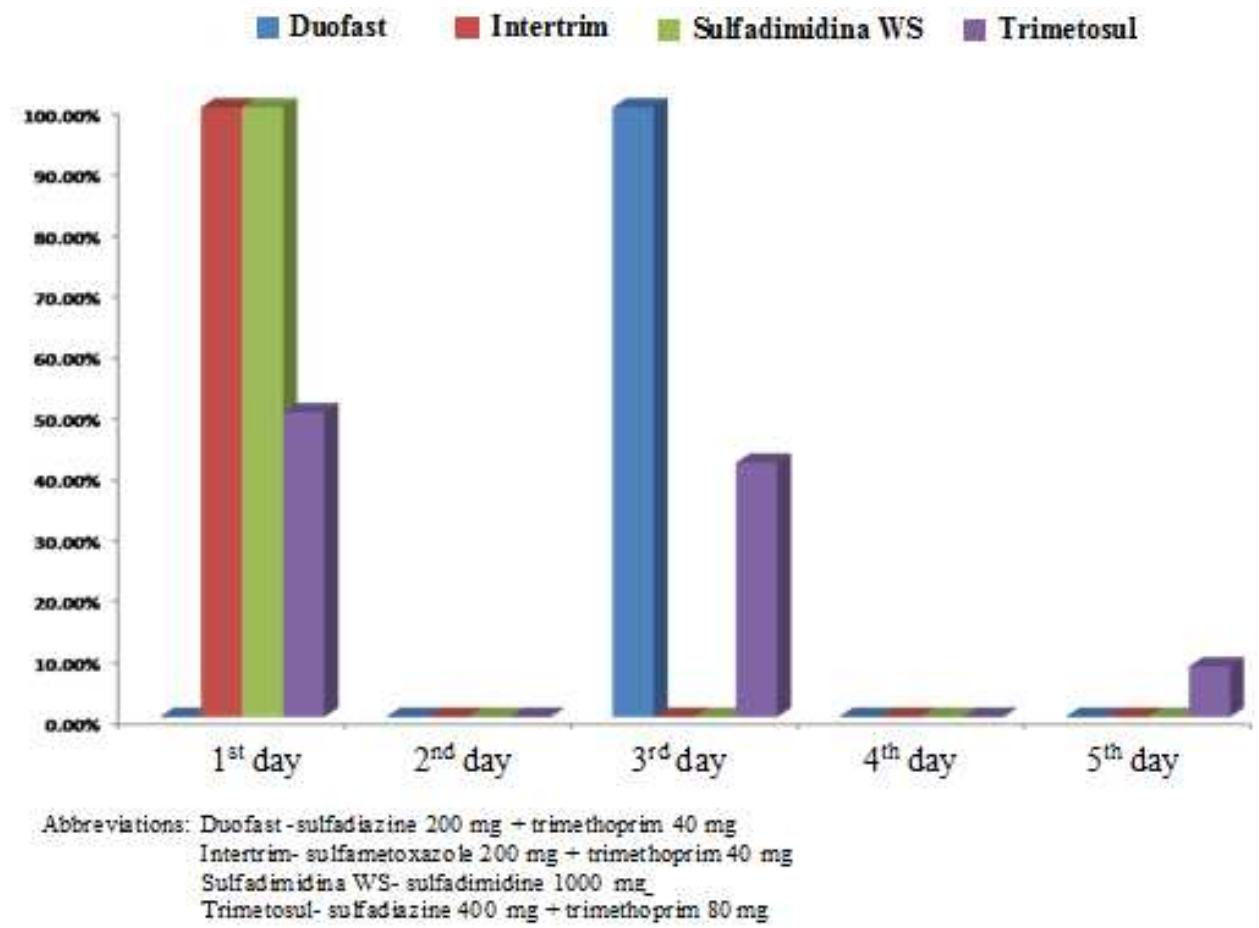

Fig. 6: The percentage of cattle treated with sulfonamides according to the number of days 


\section{DISCCUSION}

Kosova is thought to own around 150,000 dairy cows or $52 \%$ of its total cattle. Dairy cattle are the main carriers of milk production. Annual production is around 381,896 litres of milk, while milk consumption per capita is over 170 litres of milk per year [21].

The produced milk is used mainly for industrial processing benefiting from its derivatives, but also for sale in the market. Most of the processing factories cooperate with dairy farms, in this respect. However and unfortunately some of the farms act independently and sell the milk directly in the market, without consultation with the industry $[21,22]$.

The results obtained in our research clearly show that the treatment of dairy cattle is not abided by regulations. Antibiotics must be given to dairy cattle for a minimum of $5 \mathrm{~d}$ in the row using the same dose every day of the treatment in order to achieve the desired effect in cattle and ultimately in the general public.

Always for reasons of profit margins farmers often avoid abiding by regulations; fearing loss of milk, avoiding neccessary time pauses when administering drugs or giving cattle less antibiotics at short periods of treatment to avoid residue detections.

This practice weakens the cattles' immunity. It causes high doses of unhealthy residues in milk, as shown above, and ultimately increases the antibiotic resistance in general human population.

Milk consumers, especially children and pregnant women should be assured of its purity. Milk must be free of any contamination be it from bacteria or drugs in order to prevent serious harm to public health, as posed by anti-bioresistance [23].

Our study's findings show that sulfonamide residues can be detected in the early days of the treatment. This is also in accordance with several other studies.

In Germany in 2007, in a study conducted by Kress et al., the presence of sulfonamides is confirmed in $1.6 \%$ of milk samples [24].

Other study conducted by Tolentino et al., in 2005 in Mexico showed that the number of samples detected with sulfonamide residues using Elisa method amounted to $51.3 \%$ of the total number of analyzed samples [25].

Moreover, researches published by Tansakul in 2008 show that in 1998 in the US the prevalence of sulfonamide residues in raw milk was $40-70 \%$ [26].

In 1991 Sanders in Germany analyzed 2972 samples of milk with HPLC method and the presence of sulfonamides was confirmed in $1.1 \%$ of the total [27].

Smedley in 1994 when analyzing samples with confirmatory method showed that 8 samples were contaminated with sulfonamides [28].

Unlike the above data, in which a relatively increased sulfonamide presence is evidenced, other studies show a low level of residues. Reybroeck et al., relying on research conducted in Belgium in 2006, confirmed the presence of sulfonamide to $0.05 \%$ of the total number of samples analyzed. The same author a year later in 2007 in another study was unable to detect a single sulfonamide residue in samples of raw milk [29].

In other study conducted in the Netherlands, in 2000 by Abjean, using Elisa screening method in 1100 milk samples, it showed that $0.81 \%$ of them were contaminated with sulfonamide residues. Meanwhile, during the same study, the application HPLC confirmatory method failed to show any presence of antibiotics [30].

A study conducted in Turkey in 2007 by Alkan analyzed 46 samples using HPLC confirmatory method. It confirmed the presence of sulfonamide residues only in one sample to have been above the maximum limit allowed [31].

In a survey conducted by Chung, in the Republic of Korea, in 2008, out of 269 analyzed milk samples with HPLC method, only 4 showed the presence of sulfonamides [32].
Even though there are differences in the above studies [24-32], most of them conclude that drug residues are very likely to be present in milk, and advise that milk should not be used in the first days of treatment.

\section{CONCLUSION}

This study demonstrates that in the collected raw milk there were sulfonamide residues, whose level has fallen following $4 \mathrm{~d}$ of treatment of the animal. It also shows the necessary time allowed for milk consumption. During this time milk must not be consumed in order to prevent the development of antibiotic resistance in the human population. The finding of sulfonamides in the milk and the decreasing of their residue level only after $4 \mathrm{~d}$ seems to significantly influence the possibility of development of antibiotic resistance in humans who drink that milk. Moreover, milk quality control deemed for the market must be improved. In addition, antibiotics used in animals must never be used in humans too as to avoid and prevent the development of the resistance to these drugs which could seriously damage public health.

\section{ACKNOWLEDGMENT}

We would like to thank all the farmers who without hesitation helped us in the process of milk sample collection and answered our questionnaire.

\section{AUTHORS` CONTRIBUTION}

Ibraimi and Shehi were overseeing this project, had full access of the data and did take responsibility for the integrity of the data.

Study Design: Ibraimi and Shehi.

Instruction on the use of instruments for the outcome measures used in this study: Ibraimi, Shehi and Haliti.

Analysis and interpretation of data: Ibraimi, Murtezani and Haliti.

Manuscript preparation: Ibraimi and Shehi.

Statistical Analysis: Murtezani, Haliti and Ibraimi.

\section{CONFLICT OF INTERESTS}

\section{Declared none}

\section{REFERENCES}

1. Belitz HD, Grosch W, Schieberle P. Food chemistry. 4th ed. Springer; 2009. p. 498-545.

2. Jones GM. On farm tests for drug residues in milk. Department of Dairy Science, Virginia Tech; 2009. p. 401-404.

3. Soulsby EJ. Resistance to antimicrobials in humans and animals: Overusing antibiotics is not the only cause and reducing use is not the only solution. Br Med J 2005;331:1219-20.

4. Dubey MK, Bhardwaj U, Hanif M, Chopra KK, Khanna A, Saini S. Rapid detection of multidrug resistance among multidrug resistant tuberculosis suspects using line probe assay. Asian J Pharm Clin Res 2017;3:131-3.

5. Schneider K, Garrett L. Non-therapeutic use of antibiotics in animal agriculture, corresponding resistance rates, and what can be done about it. Center for Global Development; 2009.

6. Peter N, Cherian N, Thomas S, George S, Sundresh NJ. Study of prescribing pattern and use of antibiotic in the management of wound infection. Asian J Pharm Clin Res 2017;2:210-3.

7. Brackett CC, Singh H, Block JH. Likelihood and mechanisms of cross-allergenicity between sulfonamide antibiotics and other drugs containing a sulfonamide functional group. Pharmacotherapy 2004;24:856-70.

8. Long AR, Hsieh LC, Malbrough MS, Short CR, Barker SA. Multiresidue method for the determination of sulphonamides in pork tissue. J Agric Food Chem 1990;38:423-6.

9. Thomson CA, Sporns P. Direct elisas for sulfathiazole in milk and honey with special emphasis on enzyme conjugate preparation. J Food Sci 1995;60:409-14.

10. Acar J, Rostel B. Antimicrobial resistance: an overview. Rev Sci Tech Off Int Epiz 2001;20:797-810.

11. Honkanen BT, Reybroeck W. Antimicrobials in residues and contaminants in milk and milk products. Belgium; 1997. p. 26-33. 
12. Gonzalez CA, Usher KM, Brooks AE, Majors RE. Determination of sulfonamides in milk using solid-phase extraction and liquid chromatography-tandem mass spectrometry. Agilent Technologies, Inc; 2009. p. 1-5.

13. Schwarz $S$, Chaslus DE. Use of antimicrobials in veterinary medicine and mechanisms of resistance. Vet Res 2001;32:201-25.

14. Multi-screening Sulfonamides II ELISA. Netherlands cat. No; 5101SULMII.

15. Alaburda J, Ruvieri V, Shundo L, Almeida AP, Tiglea P, Sabino M. Sulfonamides in milk by high-performance liquid chromatography with pre-column derivatization and fluorescence detection. Pesq Agropec Bras 2007;42:1587-92.

16. Chauhan K, Mujawar A, Quazi I. HPTLC method development and validation for densitometric analysis of carbocisteine in drug formulation. Int J Appl Pharm 2016;8:22-5.

17. Kamala G, Vadrevu S, Valli KN. Development and validation of RP-HPLC method for simultaneous estimation of lamivudine and zidovudine in bulk. Int J Curr Pharm Res 2016;1:28-33.

18. Sivakumar P, Anbarasu K. Catalytic pyrolysis of dairy industrial waste ldpe film into fuel. Int J Chem Res 2012;3:52-5.

19. Commission Decision 2002/657/EC of 12 August 2002 implementing Council Directive 96/23/EC concerning the performance of analytical methods and the interpretation of results; 2002. p. 8-36.

20. Council Directive 96/23/EC of 29 April 1996 on measures to monitor certain substances and residues thereof in live animals and animal products and repealing Directives 85/358/EEC and 86/469/EEC and Decisions 89/187/EEC and 91/664/EEC OJ L 125, 23.5.; 1996. p. 10-32.

21. Ministry of Agriculture, Forestry and Rural Development of Kosovo, Analysis of Livestock Sector in Kosovo, DLP. Project for RandI, Pristina, Kosovo; 2009.

22. Statistical Yearbook of the Republic of Kosovo and FRY, different years. Project for RandI, Pristina, Kosovo; 2013.

23. World Health Organization. Use of antimicrobials outside human medicine and resultant antimicrobial resistance in humans. Health Topics 2002;268:1-4.
24. Kress C, Seidler C, Kerp B, Schneider E, Usleber E. Experiences with an identification and quantification program for inhibitorpositive milk sample. Anal Chim Acta 2007;586:275-9.

25. Tolentino RG, Perez MN, Gonzales GD, Leon SV, Lopez MG, Flores GP. Determination of the presence of 10 antimicrobial residues in mexican pasteurized milk. Intercsiencia 2005;30:291-4.

26. Tansakul N. A sulfadimidine model to evaluate pharmacocinetics and residues at varuous concentrations in laying hens. Hannover, Germany; 2008.

27. Sanders P, Guillot P, Dagorn M, Delmas JM. Liquid chromatographic determination of chloramphenicol in calf tissues: studies of stability in muscle, kidney and liver. J Assoc Off Anal Chem 1991;74:483-6.

28. Smedley MD. Liquid chromatographic determination of multiple sulfonamide residues in bovine milk: collaborative study. J AOAC Int 1994;77:1112-2.

29. Reybroeck W. Screening for residues of antibiotics and chemotherapeutics in milk and honey. Faculty of Veterinary Medicine, University of Ghent, Belgium; 2010.

30. Abjean JP, Delepine B, Hurtaud DP. Qualitative or quantitative methods for residue analysis? A strategy for drug residue monitoring. Euro Residue IV Conference, Veldhoven, Netherlands; 2000.

31. Alkan P. The confirmation of commercial kits used in the detection of antibiotics in milk with HPLC (High-Pressure Liquid Chromatography). Graduate School of Engineering and Sciences of Izmir Institute of Technology, Izmir, Turkey; 2007.

32. Chung HH, Lee JB, Chung YH, Lee KG. Analysis of sulfonamide and quinolone antibiotic residues in Korean milk using microbial assays and high-performance liquid chromatography. Department of Food Science and Technology, Dongguk University, Republic of Korea; 2008.

\section{How to cite this article}

- Zana Ibraimi, Agim Shehi, Ardiana Murtezani, Fehim Haliti. The possibility of development of antibiotic resistance from massive and uncontrolled use of sulfonamides in milk. Int J Pharm Pharm Sci 2017;9(4):207-211. 